\title{
Antifungal Efficacy of Aqueous and Gaseous Ozone in Root Canals Infected by Candida albicans
}

\author{
Ihsan Hubbezoglu ${ }^{1, *}$, Recai Zan ${ }^{2}$, Tutku Tunç ${ }^{3}$, Zeynep Sumer ${ }^{3}$, Feridun Hurmuzlu ${ }^{1}$ \\ ${ }^{1}$ Cumhuriyet University, Faculty of Dentistry, Department of Restorative Dentistry, Sivas, Turkey \\ 2 Cumhuriyet University, Faculty of Dentistry, Department of Endodontics, Sivas, Turkey \\ ${ }^{3}$ Cumhuriyet University, Faculty of Medicine, Department of Microbiology, Sivas, Turkey \\ ${ }^{*}$ Corresponding author: Ihsan Hubbezoglu, Cumhuriyet University, Faculty of Dentistry, Department of Restorative Dentistry, Sivas, Turkey. Tel:+90-5428160044, Fax:+90-3462191235,
} E-mail: hubbezoglu@yahoo.com.

Received: September 12, 2012; Revised: January 11, 2013; Accepted: January 23, 2013

\begin{abstract}
Background: Candida albicans is one of the important microorganism which can be isolated from normal flora in the mouth. The resistance of $C$. albicans against disinfectants like ozone can reduce success rate of root canal treatments.

Objectives: The current study aimed to investigate the antifungal efficacy of aqueous and gaseous ozone in human root canals infected by C.albicans.

Materials and Methods: Fifty single-root mandibular premolar teeth were selected. The teeth were prepared and sterilized. C. albicans were incubated in root canals and kept at $37^{\circ} \mathrm{C}$ for $24 \mathrm{~h}$. The teeth were divided into one positive, one negative control, and three experimental groups ( $\mathrm{n}=10$ ). Group 1, saline (positive control); Group 2, sodium hypochlorite (NaOCl) (negative control); Group 3, aqueous ozone with manual technique (4 mg/L); Group 4, aqueous ozone with ultrasonic technique (4 mg/L)and Group 5, gaseous ozone. Disinfection procedures were performed during $300 \mathrm{~s}$ to ensure standardization among all the working groups. Paper points, placed in the root canals before and after disinfection procedures, were transferred in Eppendorf tubes containing $0.5 \mathrm{ml}$ of brain heart infusion broth. Then 50- $\mu \mathrm{L}$ suspension was inoculated onto Sabouraud dextrose agar. Microbial colonies were counted and data were evaluated statistically with using one-way ANOVA and Tukey's tests.

Results: A statistically significant difference was found between antifungal activities of gaseous ozone group and $\mathrm{NaOCl}$ group ( $\mathrm{P}<$ 0.05). Additionally, although no statistically significant differences were found among aqueous ozone groups (manual and ultrasonic techniques) and the NaOCl group ( $\mathrm{P}>0.05)$, few fungi were found in the aqueous ozone with manual technique group.

Conclusions: When gaseous ozone was used alone in root canals, its antifungal effect was not sufficient. However, applying aqueous ozone with ultrasonic technique showed stronger antifungal effects than aqueous ozone with manual technique in root canals.
\end{abstract}

Keywords: Ozone; Disinfection; Root Canal; Microorganism

\section{Background}

The success of endodontic treatment is directly influenced by elimination of microorganisms in root canals. Effective antimicrobial irrigations are too significant during root canal preparation, because they aid in cleaning the root canal, lubricating the files, and flushing out debris $(1,2)$. Ideal irrigants should have strong antimicrobial effect but nontoxic to the periapical tissues when they run over from the apex (3). It is difficult to eliminate all the microorganisms and throw out the organic debris from the root canal system regardless of the irrigant and instrumentation $(4,5)$. Generally in endodontics, 5.25\% $\mathrm{NaOCl}$ was superior in its antimicrobial abilities compared with the other used irrigants (6). The concentration and toxicity of $\mathrm{NaOCl}$ is directly proportional (7). Using low concentrations of $\mathrm{NaOCl}$ not only reduce cyto- toxic and irritating properties, but also decrease antibacterial effects (8).

Recently, ozone has become one of the most important disinfecting agents used in dentistry. It can be administered in either gaseous or aqueous form. Both of them may act like powerful antimicrobial agents that are strong and fast oxidizers of cell walls and cytoplasmatic membranes of microorganisms. For these reasons, ozone is considered as one of the best bactericidal, antiviral, and antifungal agents $(9,10)$. The gaseous form of ozone is a respiratory irritant, and can also cause dryness in the mouth and throat, headache, chest restriction, and coughing (11). Besides, the antimicrobial efficacy of gaseous ozone has been emphasized in some studies. For instance, in a research, gaseous ozone/oxygen mixture with a low dose completely inhibited the growth of all

Implication for health policy/practice/research/medical education:

The article will help clinicians to indicate the antifungal effect of gaseous and aqueous ozone as disinfectant agent instead of NaOCl in root canals

Copyright @ 2013, Ahvaz Jundishapur University of Medical Sciences; Licensee Kowsar Ltd. This is an Open Access article distributed under the terms of the Creative Commons Attribution License (http://creativecommons.org/licenses/by/3.0), which permits unrestricted use, distribution, and reproduction in any medium, provided the original work is properly cited. 
potentially pathogenic bacterial strains that cultivatein Petri dishes (12). The other studies also determined the gaseous ozone effect against microorganisms in the root canals, complete elimination of bacteria could not be achieved (13-15).

Aqueous ozone essentially shows no toxicity to oral cells as in vitro (10). Because it is highly unstable, aqueous ozone should be used as soon as possible after being mixed. It is very difficult to keep this mixture at the same concentration for a long time (16). Many studies demosrated the antimicrobial effect of aqueous ozone, emphasized insufficient disinfectant effect of aqueous ozone against pathogenic microorganisms in dental plaque (10), root canals (13) and acrylic resin plates (17). Due to the these properties, ozone may be used as a new alternative disinfectant agent in root canals but there is also the need to investigate whether it has the same effect like $\mathrm{NaOCl}$ or not.

\section{Objectives}

The current study aimed to investigate the antifungal effects of aqueous ozone administered via manual or ultrasonic irrigation techniques and gaseous ozone against Candida albicans in root canals. Moreover, data were compared with antifungal effects of saline (positive control) and $\mathrm{NaOCl}$ (negative control) groups for the disinfection of root canals infected by C. albicans.

\section{Materials and Methods}

\subsection{Sample Preparation}

For orthodontic or periodontal reasons, in the present study, 50 single-rooted single-canal human mandibular permanent premolar teeth that were freshly extracted without caries and restorations, were used. Digital radiographs of teeth were taken from buccal and approximal directions to determine the number and morphology of canals. Informed consent was obtained from the patients before starting the research, and the study was approved by the Local Ethics Committee on Human Research of Cumhuriyet University.

Having been cleaned of residues, freshly extracted teeth were kept at $+4^{\circ} \mathrm{C}$ and $0.9 \%$ saline solution until the study was applied. Below the level of enamel-cementum junction, the coronal portions of the teeth were cut using sterile diamond discs under cooling water to obtain a 14$16 \mathrm{~mm}$ length of each root. Then the root canals were entered with \#15 K-File (Mani Inc, Tochigi, Japan) hand tools, and the path of canal was determined. The tip of the file was used to measure the length of each canal until it became visible in the apical foramen. Then it was withdrawn $1 \mathrm{~mm}$ from the measured length. The root canals were shaped with ProTaper (Dentsply, Tulsa Endodontics, OK, USA) rotary Ni-Ti instruments using the crown-down method by the electric motor (Denta ports DP-ZX, J. Mori- ta MFG, CORP, Kyoto, Japan). Firstly, the coronal third of the roots were expanded with SX files. Secondly, the median third of roots were reached with S1 and S2 files. The F1, F2, and F3 files were applied, respectively, to shape the apical third of the canals. The canals were irrigated with 1 $\mathrm{ml}$ of $5.25 \%$ solution of $\mathrm{NaOCl}$ after the usage of each file.

The roots were irrigated with 17\% EDTA, 5.25\% NaOCl, and distilled water, respectively, for $10 \mathrm{~min}$ to remove the smear layer formed during root canal preparation and then were dried with paper point. The bottles were placed in an autoclave to ensure sterilization for $20 \mathrm{~min}$ at $121^{\circ} \mathrm{C}$ (Melag, Euroklav 23V-S, Germany). Then 3-fold nail polish (L'Oreal Jet-Set Diamond, Paris, France) was applied to whole root surfaces of the teeth, including the root tips. Rubber caps embedded in the teeth were sterilized by Ethylene oxide and then placed in bottles.

\subsection{Microbiologic Procedures}

C. albicans (ATCC 10231) strains were cultured in the liquid nutrient media brain heart infusion broth and were incubated at $37^{\circ} \mathrm{C}$ for $24 \mathrm{~h}$. Prior to the each experiment, 0.5 McFarland turbidity was set with kristalspec $\mathrm{TM}$, and McFarland standard number 0.5 was used to improve broth to obtain fungal growth in the amount of 1.5 X 104 colony forming unit (CFU/mL). Then $10 \mu$ of the yeast culture was transferred to the mechanically expanded lumen of the root canal using a sterile micropipette and then kept at $37^{\circ} \mathrm{C}$ for $24 \mathrm{~h}$. The sterile paper points (Dentsply, Maillefer) were placed in the root canals inoculated with yeast to control fungal growth. Paper points were left for $5 \mathrm{~min}$ within the root canal, soaked with the broth. Then paper points were put into sterile eppendorf tubes containing $0.5 \mathrm{ml}$ brain heart infusion broth (Merck 1.13825). After waiting for $15 \mathrm{~min}, 50 \mu \mathrm{l}$ of liquid medium was taken with a sterile micropipette from the Eppendorf with mixed vortex and was smear-planted to solid medium (Sabouraud dextrose agar), which was split before and after the disinfection applications.

\subsection{Experimental Groups}

Group 1, Saline (positive control) group: Infected root canals were irrigated for $300 \mathrm{~s}$ with $0.9 \%$ saline solution.

Group 2, NaOCl (negative control) group: Infected root canals were irrigated for $300 \mathrm{~s}$ with $5.25 \% \mathrm{NaOCl}$.

Group 3, Aqueous ozone with manual technique group: Aqueous ozone was obtained from the custom-made ozone generator (TeknO3zone, Izmir/Turkey) by the TeknO3zone company (Figure $1 \mathrm{a}$ ). The ozone density of the distilled water was measured with the probe in the reactor tank (Figure $1 \mathrm{~b}$ ) and was shown by the digital indicator on the generator. Infected root canals were irrigated for $300 \mathrm{~s}$ with $4 \mathrm{mg} / \mathrm{L}$ aqueous ozone (TeknO3zone, Izmir/Turkey). Control of power was maintained automatically by the automatic balancing system.

Group 4, Aqueous ozone with ultrasonic technique 
group: Aqueous ozone was obtained from the custommade ozone generator (TeknO3zone, Izmir/Turkey) by the TeknOzzone company. Infected root canals were irrigated with $4 \mathrm{mg} / \mathrm{L}$ aqueous ozone and simultaneously combinated with ultrasonication that was obtained from VDW. ULTRA (Satelec, Merignac Cedex, France) (Figure 1 c) device for $300 \mathrm{~s}$.



Figure 1. a) Aqueous Ozone Generator b) Reactor Tank c) Application of Aqueous Ozone With Ultrasonic Technique

Group 5, Gaseous ozone group: Gaseous ozone was obtained from an ozone generator (Heal Ozone, KaVo, Germany) by vacuum to the root canals for $300 \mathrm{~s}$ with a hand piece on which was fixed $5 \mathrm{~mm}$ diameter silicone caps and endodontic cannulas (Figure 2).

\subsection{Antifungal Evaluation}

Root canals were contaminated and then waited for 24 h. Paper points were placed and waited for five min in root canals before the application of irrigation to control the growth of microorganisms. They east counting of samples was done to ensure standardization and the CFU values of samples, under 1x104 CFU/mL, were excluded.

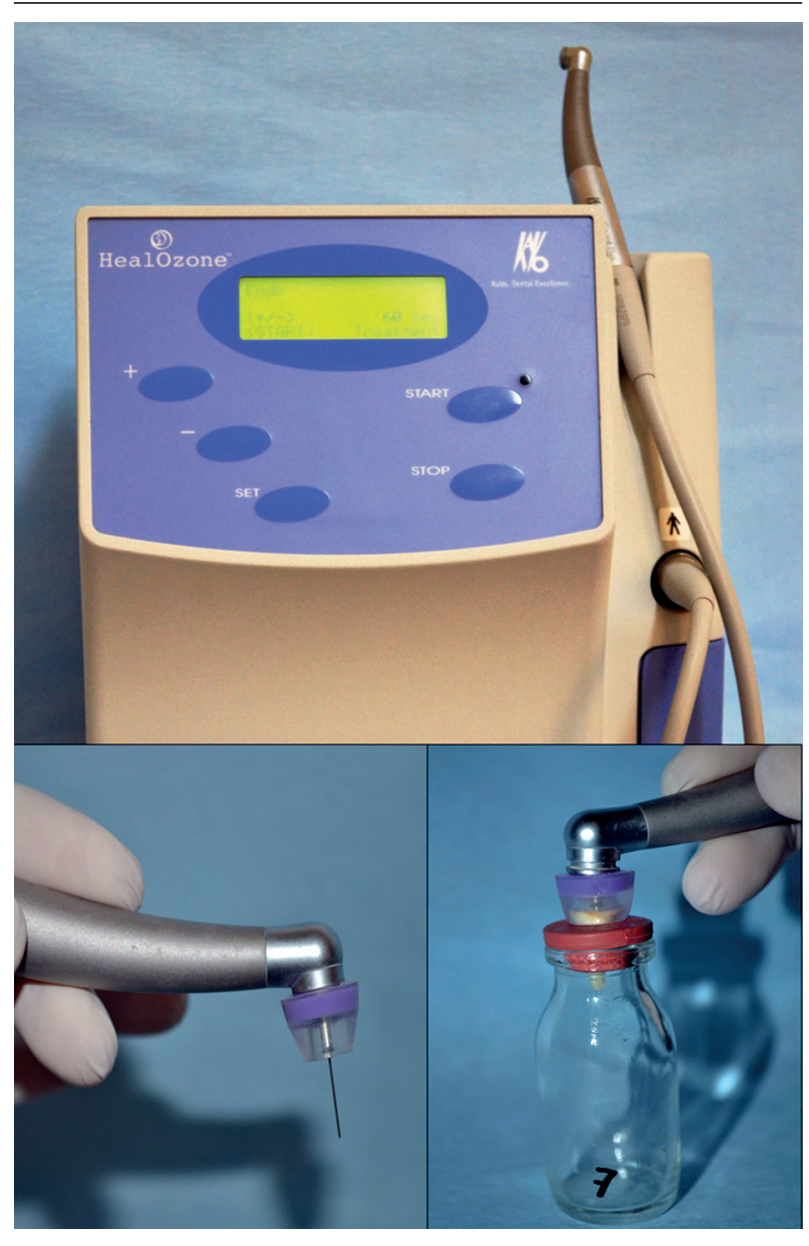

Figure 2. Application Technique of Silicone Caps and Endodontic Cannulas to the Teeth

After the application of irrigation, CFU counting of the breeding colonies of microorganisms were performed in Sabouraud dextrose agar. Then log CFU values were calculated.

\subsection{Statistical Analysis}

SPSS statistical software program (14.0 Version, SPSS Inc., Chicago, USA) was employed to analyze the variation data of irrigation solutions. The data were subject to statistical analysis among five different irrigation solutions using one-way analysis of variance (ANOVA). When significant differences were observed, Tukey post hoc test was applied to examine pair wise differences at a significance level of 0.05 .

\section{Result}

Mean, standard deviation, and median values obtained after application of irrigation are shown in Table 1. Statistical comparison of log CFU mean values are shown in Table 1. 
Table 1. The Data Values of Log CFU Enumeration Obtained After the Application Belongs to the Group of C. albicans and Statistical Comparisons Among Groups

\begin{tabular}{lll}
\hline Groups $^{\text {a }}$ & Mean (SD), Log CFU L $^{-1}$ & Median, Log CFU $\mathbf{~ L}^{-1}$ \\
\hline Group 1 $^{\text {b }}$, Saline (Positive Control) & $2.700(0.483)$ & 3 \\
Group 2 $^{\text {b }}$, NaOCl (Negative Control) & $0.000(0.000)$ & 0 \\
Group 3 $^{\text {b }}$, Aqueous Ozone With Manuel Technique & $0.300(0.105)$ & 0 \\
Group 4 $^{\mathrm{b}}$, Aqueous Ozone With Ultrasonic Technique & $0.000(0.000)$ & 0 \\
Group $5^{\text {, Gaseous Ozone }}{ }^{\mathrm{b}}$, Gaseous Ozone & $1.100(0.876)$ & 1 \\
\hline
\end{tabular}

${ }^{\mathrm{a}} \mathrm{CFU}$, colony-forming units; By the one way ANOVA, $\mathrm{F}=44.868 ; \mathrm{P}=0.000(\mathrm{P}<0.05)$.

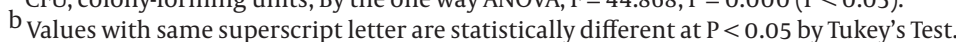

The current study investigated the antifungal activities of disinfectant agents applied to the root canals, infected by $C$. albicans. There was a statistically significant difference between the gaseous ozone group and $\mathrm{NaOCl}$ (negative control) group $(\mathrm{P}<0.05)$. Additionally, although no statistically significant differences were found among aqueous ozone groups (manual and ultrasonic techniques) and the $\mathrm{NaOCl}$ group ( $\mathrm{P}>0.05)$, few fungi were found in 2 of 10 examples in the aqueous ozone with manual technique group. There were statistically significant differences among the saline group and all other groups $(P<0.05)$. As a result, when gaseous ozone was used alone in root canals, its antifungal effect was insufficient. However, applying aqueous ozone with ultrasonic technique showed stronger antifungal effects than aqueous ozone with manual technique in root canals.

\section{Discussion}

In endodontic treatments, one of the most important purposes is the removal of pulp and dentine debris. Cleaning the root canal system is done by chemo mechanic preparation in which the mechanical preparation and irrigation are applied together. For this reason, to achieve ideal treatment, the properties of irrigation solutions are highly important for the root canal system. Today, the most commonly used irrigation solution in endodontic treatments is sodium hypochlorite (18). Although it dissolves necrotic tissue and eliminates microorganisms effectively in high concentrations, this solution is very cytotoxic and harmful to living oral tissues. Consequently, current endodontic treatments should be effective and with virtually no side effects for disinfection of the root canal (18-20).

Fidalgo et al., (21) evaluated the antimicrobial activity of different root canal irrigants against $C$. albicans. The researcher found a slight reduction of the number of C. albicans after irrigation of $\mathrm{NaOCl}$ with $2.5 \%$ concentration. Furthermore, they observed a complete elimination of $C$. albicans following irrigation with 5.25\% NaOCl. Similarly, in the present study, $10 \mathrm{ml} \mathrm{NaOCl}$ at a $5.25 \%$ concentration was used for $300 \mathrm{~s}$ to ensure complete disinfection of the root canals. This concentration of $\mathrm{NaOCl}$ com- pletely eliminated the $C$. albicans. Consequently, $\mathrm{NaOCl}$ as an irrigation solution showed strong antifungal effect. HealOzone or OziCure generators are frequently used to obtain gaseous ozone. The aspirator on the generator should absorb the ozone back into the environment. In the HealOzone generator, gaseous ozone is absorbed and then converted into the gaseous oxygen before releasing the ozone into the environment. In case of gas leakage, the system automatically stops the application of gaseous ozone. When the OziCure generator is used without sufficient absorption, ozone gas levels can reach undesirable levels. For these reasons, is safer to use the HealOzone generator rather than the OziCure generator $(22,23)$.

Huth et al. (13) investigated the antimicrobial efficacy of gaseous and aqueous ozone against $C$. albicans. Most of C. albicans were eliminated after application of gaseous ozone for $60 \mathrm{~s}$. Moreover, when aqueous ozone application was conducted at high concentration $(20 \mathrm{mg} / \mathrm{L})$ for a minute, approximately $96 \%$ of these microorganisms were eliminated. In another study, Kustarci et al. (14) evaluated the antimicrobial activity of potassium-titanyl-phosphate (KTP) laser and gaseous ozone (2100 ppm/ $\mathrm{min}$ ) in root canals for $120 \mathrm{~s}$. Additionally, Muller et al. (15) also explored resistance of ozone against bacteria. They applied gaseous ozone for $60 \mathrm{~s}$. However, complete elimination of bacteria could not be achieved in these studies (13-15).

After reviewing the results of the application time in these studies (13-15), the current study investigated the antifungal effect of gaseous ozone obtained from HealOzone (2100 ppm/min) on root canals infected with C. albicans for $300 \mathrm{~s}$. According to the results of the present study, gaseous ozone eliminated most of the C. albicans. The results obtained by the abovementioned studies (13-15) exhibited similar antimicrobial efficacy compared to the results of present study. Besides, although the present study used longer application time, complete disinfection was not achieved. It can be the result of insufficient gaseous ozone penetration into the tubules of root canals. Cardosa et al. (24) evaluated the antimicrobial effect of aqueous ozone ( $3.3 \mathrm{mg} / \mathrm{L}, 300 \mathrm{~s}$ ) against C. albicans and Enterococcus faecalis. A significant reduction was 
observed in the number of C. albicans and E. faecalis when samples were immediately taken from the root canals. Furthermore, aqueous ozone as an irrigant agent was effective against $C$. albicans and E. faecalis, but it was not able to neutralize all the microorganisms.

Arita et al. (17) examinated the antimicrobial effect of aqueous ozone ( $4 \mathrm{mg} / \mathrm{L}$ ) applied with ultrasonic techniques at different times against $C$. albicans on acrylic resin plates. Although there was a slight reduction in the number of fungi after $60 \mathrm{~s}$, it took more than $30 \mathrm{~min}$ to achieve complete microbial elimination. Nagayoshi et al. (10) studied the antimicrobial activity of aqueous ozone ( $4 \mathrm{mg} / \mathrm{L}$ ) on oral microorganisms and dental plaque. As a result, although $2 \mathrm{mg} / \mathrm{L}$ of aqueous ozonefor $120 \mathrm{~s}$ had a remarkable antimicrobial effect, $4 \mathrm{mg} / \mathrm{L}$ of aqueous ozone killed the whole $C$. albicans.

In the present study, aqueous ozone with ultrasonic technique indicated stronger antifungal effect than aqueous ozone with manual technique. Additionally, ultrasonication of aqueous ozone was found as effective as $\mathrm{NaOCl}$ against $C$. albicans. The results of previous studies $(10,17,24)$ support the results of the present study. Unlike these studies $(10,17,24)$ the current study used the root canals of extracted human teeth and the direct counting method of fungi, which was carried out after $24 \mathrm{~h}$ of incubation at the microbiological stage.

According to the findings of the current study, gaseous ozone can be used for disinfection of infected root canals, but it is not adequate when used alone for root canal sterilization. Moreover, using aqueous ozone combined with ultrasonic technique is highly effective in terms of disinfection of the root canal and may be used instead of $\mathrm{NaOCl}$ in root canals. Further research is needed to investigate the availability of aqueous ozone that has more adequate properties for clinical endodontic treatments.

\section{Acknowledgements}

The authors would like to express their appreciations to Assoc. Prof. Dr. Jale Tanalp for reviewing the manuscript and providing suggestions.

\section{Authors' Contribution}

R. Zan was main researcher; I. Hubbezoglu was supervisor of the thesis and corresponding author; Z. Sumer was advisor of the thesis.

\section{Financial Disclosure}

All authors declare that they have no conflict of interest.

\section{Funding/Support}

This work was supported by Scientific Research Unit of Cumhuriyet University (CUBAP), Project Nr. DIS-086.

\section{References}

1. Bystrom A, Sundqvist G. Bacteriologic evaluation of the effect of 0.5 percent sodium hypochlorite in endodontic therapy. Oral Surg Oral Med Oral Pathol.1983;55(3):307-12.

2. Estrela C, Estrela CR, Barbin EL, Spano JC, Marchesan MA, Pecora JD. Mechanism of action of sodium hypochlorite. Braz Dent $J$. 2002;13(2):113-7.

3. Yesilsoy C, Whitaker E, Cleveland D, Phillips E, Trope M. Antimicrobial and toxic effects of established and potential root canal irrigants. J Endod. 1995;21(10):513-5.

4. Baumgartner JC, Brown CM, Mader CL, Peters DD, Shulman JD. A scanning electron microscopic evaluation of root canal debridement using saline, sodium hypochlorite, and citric acid. J Endod. 1984;10(11):525-31.

5. Smith JJ, Wayman BE. An evaluation of the antimicrobial effectiveness of citric acid as a root canal irrigant. $J$ Endod. 1986;12(2):54-8.

6. Ayhan H, Sultan N, Cirak M, Ruhi MZ, Bodur H. Antimicrobial effects of various endodontic irrigants on selected microorganisms. Int Endod J.1999;32(2):99-102.

7. Clarkson RM, Moule AJ. Sodium hypochlorite and its use as an endodontic irrigant. Aust Dent J.1998;43(4):250-6.

8. Turkun M, Cengiz T. The effects of sodium hypochlorite and calcium hydroxide on tissue dissolution and root canal cleanliness. Int Endod J.1997;30(5):335-42.

9. Kim JG, Yousef AE, Dave S. Application of ozone for enhancing the microbiological safety and quality of foods: a review. J Food Prot. 1999;62(9):1071-87.

10. Nagayoshi M, Fukuizumi T, Kitamura C, Yano J, Terashita M, Nishihara T. Efficacy of ozone on survival and permeability of oral microorganisms. Oral Microbiol Immunol. 2004;19(4):240-6.

11. McDonnell WF, Horstman DH, Hazucha MJ, Seal E, Jr, Haak ED, Salaam SA, et al. Pulmonary effects of ozone exposure during exercise: dose-response characteristics. J Appl Physiol. 1983;54(5):134552.

12. Fontes B, Cattani Heimbecker AM, de Souza Brito G, Costa SF, van der Heijden IM, Levin AS, et al. Effect of low-dose gaseous ozone on pathogenic bacteria. BMC Infect Dis. 2012;12:358.

13. Huth KC, Quirling M, Maier S, Kamereck K, Alkhayer M, Paschos $\mathrm{E}$, et al. Effectiveness of ozone against endodontopathogenic microorganisms in a root canal biofilm model. Int Endod J. 2009;42(1):3-13.

14. Kustarci A, Sumer Z, Altunbas D, Kosum S. Bactericidal effect of KTP laser irradiation against Enterococcus faecalis compared with gaseous ozone: an ex vivo study. Oral Surg Oral Med Oral Pathol Oral Radiol Endod. 2009;107(5):e73-9.

15. Muller P, Guggenheim B, Schmidlin PR. Efficacy of gasiform ozone and photodynamic therapy on a multispecies oral biofilm in vitro. Eur J Oral Sci. 2007;115(1):77-80.

16. Nogales CG, Ferrari PH, Kantorovich EO, Lage-Marques JL. Ozone therapy in medicine and dentistry. J Contemp Dent Pract. 2008;9(4):75-84.

17. Arita M, Nagayoshi M, Fukuizumi T, Okinaga T, Masumi S, Morikawa $M$, et al. Microbicidal efficacy of ozonated water against Candida albicans adhering to acrylic denture plates. Oral Microbiol Immunol. 2005;20(4):206-10.

18. Harrison JW. Irrigation of the root canal system. Dent Clin North Am. 1984;28(4):797-808.

19. Abou-Rass M, Oglesby SW. The effects of temperature, concentration, and tissue type on the solvent ability of sodium hypochlorite. J Endod. 1981;7(8):376-7.

20. Hauman CH, Love RM. Biocompatibility of dental materials used in contemporary endodontic therapy: a review. Part 2. Root-canal-filling materials. Int Endod J. 2003;36(3):147-60.

21. Fidalgo TK, Barcelos R, Portela MB, Soares RM, Gleiser R, Silva-Filho FC. Inhibitory activity of root canal irrigants against Candida albicans, Enterococcus faecalis and Staphylococcus aureus. Braz Oral Res. 2010;24(4):406-12.

22. Baysan A, Whiley RA, Lynch E. Antimicrobial effect of a novel ozone- generating device on micro-organisms associated with primary root carious lesions in vitro. Caries Res. 2000;34(6):498- 
501.

23. Millar BJ, Hodson N. Assessment of the safety of two ozone delivery devices. J Dent. 2007;35(3):195-200.

24. Cardoso MG, de Oliveira LD, Koga-Ito CY, Jorge AO. Effectiveness of ozonated water on Candida albicans, Enterococcus faecalis, and endotoxins in root canals. Oral Surg Oral Med Oral Pathol Oral Radiol Endod. 2008;105(3):e85-91.
Please cite this paper as: Hubbezoglu I, Zan R, Tunç T, Sumer Z, Hurmuzlu F. Antifungal Efficacy of Aqueous and Gaseous Ozone in Root Canals Infected by Candida albicans. Jundishapur J Microbiol. 2013; 6(5):e8150. DOI: 10.5812/jjm.8150 